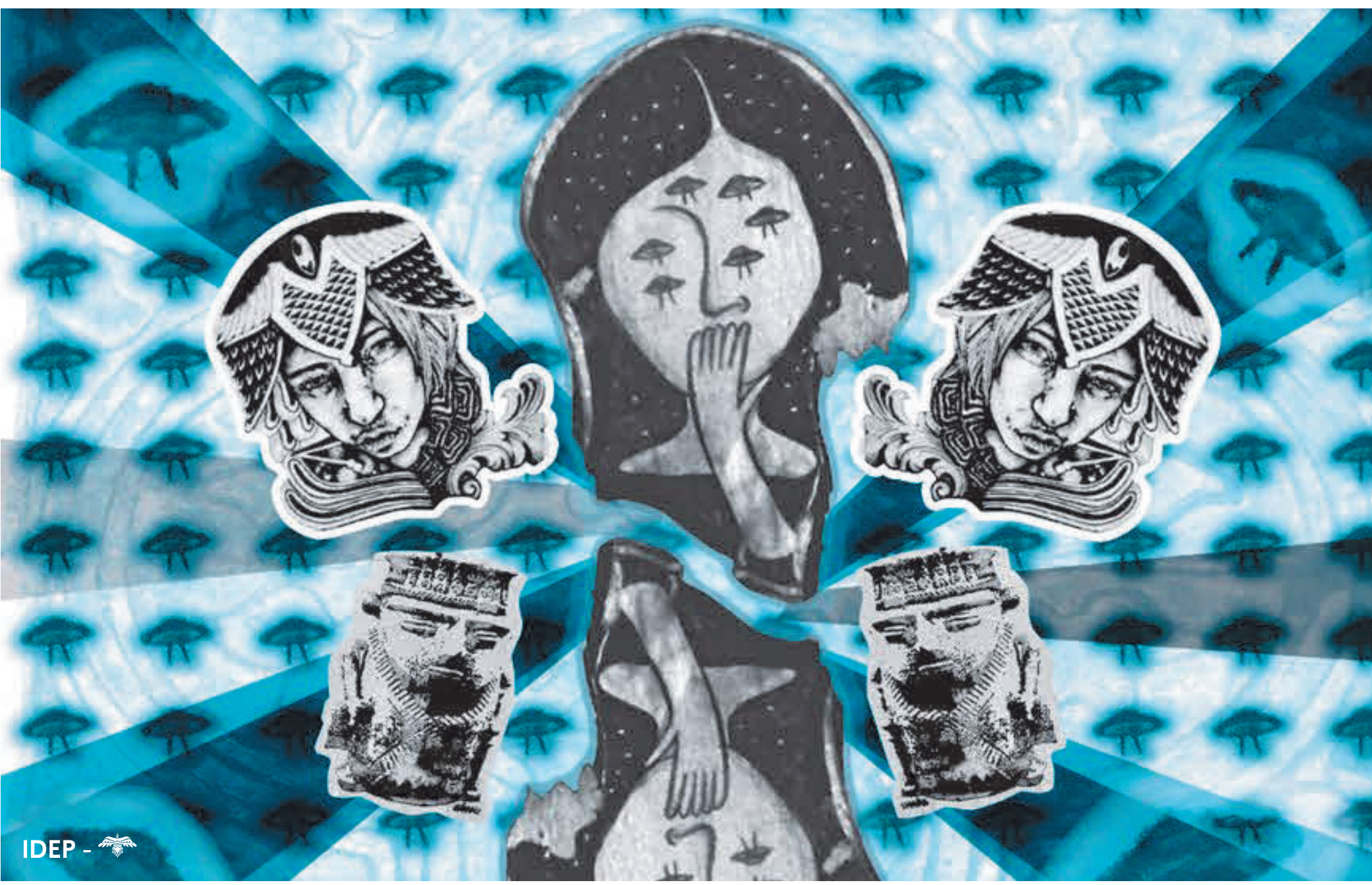

\title{
Interpelaciones contemporáneas desde la documentación narrativa co-diseñada de la praxis pedagógica. Reconfiguraciones del desarrollo profesional
}

Contemporary interpellations from the co-designed narrative documentation of pedagogical praxis. Reconfigurations of professional development

Interpelações contemporâneas da documentação narrativa co-projetada da práxis pedagógica. Reconfigurações do desenvolvimento profissional 
Tema: Ser maestros y maestras hoy (Volumen I)

\section{Ana Cristina Pace ${ }^{1}$}

Supervisora Escolar de escuelas públicas del Nivel Inicial, Ciudad Autónoma de Buenos Aires. Maestranda en el área de Educación: Tecnología Educativa y Pedagogías Críticas, Universidad de Buenos Aires. Licenciada Fonoaudióloga, Universidad de Buenos Aires, Argentina; correo electrónico: ach942pac@gmail.com

\section{DOI: https://doi.org/10.36737/01230425.v1.n36.2019.2121}

Fecha de recepción: 25 de enero de 2018 / Fecha de aprobación: 3 de abril de 2019

\begin{abstract}
Resumen
El presente trabajo intenta contribuir a las interpelaciones contemporáneas al universo escolar, que se desarrollan a partir de documentaciones narrativas co-diseñadas delapraxispedagógica. En esos movimientos se pretende identificar intervenciones generadas en algunas escuelas públicas del nivel inicial en la Ciudad de Buenos Aires y visibilizar reconfiguraciones del desarrollo profesional docente, entendido como formación continua de los sujetos que debaten saberes y posicionamientos político-pedagógicos. En este contexto, se inscriben las propuestas mediatizadas con tecnologías, habilitando construcciones de conocimientos e interpretaciones situadas del discurso autobiográfico de sus autores.
\end{abstract}

\section{Palabras clave:}

Formación docente, experiencia, investigación pedagógica, documentación narrativa codiseñada, desarrollo profesional docente.

\section{Abstract}

The present work tries to contribute to the contemporary interpellations to the scholastic universe that are developed from co-designed narrative documentations of the pedagogical praxis. In these movements it is intended to identify interventions generated in some public schools of the Initial Level of the City of Buenos Aires and to visualize reconfigurations of professional teacher development, understood as continuous training of the subjects that debate knowledge and political-pedagogical positions. In this context, mediated proposals with technologies are inscribed, enabling constructions of knowledge and interpretations located, from the autobiographical discourse of their authors.

\section{Keywords:}

Teacher training, experience, pedagogical research, co-designed narrative documentation, professional teacher development.

\section{Resumo}

O presente trabalho procura contribuir para as interpelações contemporânea sao universo escolar, que são desenvolvidas a partir de documentações narrativas coprojetadas da práxis pedagógica. Nestes movimentos pretende-se identificar intervenções geradas em algumas escolas públicas do Nível Inicial da Cidade de Buenos Aires e visualizar as reconfigurações do desenvolvimento do profesor profissional, entendido como formação contínua dos sujeitos que debatem conhecimentos e posições político-pedagógicas. Nesse contexto, inscrevemse propostas mediadas por tecnologias, posibilitando construções de saberes e interpretações localizadas, a partir do discurso autobiográfico de seus autores.

\section{Palavras-chave:}

Formação de professores, experiência, investigação pedagógica, documentação narrativa co-desenho, desenvolvimento profissional de profesores. 
Interpelaciones contemporáneas

desde la praxis pedagógica

- 1 presente trabajo intenta contribuir a las interpelaciones contemporáneas al universo escolar, a partir de la construcción de documentaciones narrativas co-diseñadas de la praxis pedagógica. Con esa intención se recuperan aspectos epistemológicos que definen cómo la investigación cualitativa, la experiencia educativa (Contreras y Pérez de Lara, 2010) y la reconstrucción pedagógica por parte de sus autores, interpelan al mundo hegemónico escolar mientras se configuran como estrategia de indagación y resemantización democrática, tensionando saber y poder del discurso en el campo pedagógico.

La recreación del lenguaje con que se denomina el mundo pedagógico emerge como forma de intervención política en el campo público de la educación, provocando procesos simultáneos de reconfiguración de posiciones de sujeto (Laclau, 1996) que se desarrollan en comunidad y disputan a la hegemonía en el campo de la pedagogía (Santos, 2008) a través de la recreación de los discursos y saberes pedagógicos. Un universo de narrativas se piensa como una particular investigación pedagógica (Contreras y Pérez de Lara, 2010), como un proceso y una experiencia de indagación y reflexión acerca del sentido pedagógico de la experiencia.

En Latinoamérica, frente a políticas y discursos tecnocráticos relacionados con la producción y validación del conocimiento, se constituyeron movimientos y redes de docentes con el propósito de reconfigurar la tradición crítica y reconstruir experiencias de la región. Éstos se proclaman como alternativas innovadoras de intervención político-pedagógica en el campo educativo y disputan sentidos y significados acerca de las formas de nombrar y hacer la educación.

Se destacan en estas iniciativas las redes de docentes de América Latina que realizan experiencias colectivas de investigaciónformación-acción participantes y en colaboración. Así, podríamos considerar a la formación como un "encuentro con el otro, como construcción de relaciones de colaboración y como procesos de transformación subjetiva en el marco de comunidades de aprendizaje y desarrollo profesional entre pares" (Suárez, 2007).

Entre los movimientos que comparten experiencias de la praxis pedagógica en una comunidad de discursos y prácticas educativas, se encuentra el movimiento de La Expedición en Colombia, el cual aprende permanentemente en tanto que permite descubrir la novedad (Expedición Pedagógica Nacional, 2005) de la "geopedagogía", es decir, "la forma de existencia de la pedagogía en el lugar, que considera la tierra, el mundo y en él la escuela y el maestro como objetos de pedagogía” (Martínez y Peña, 2009).

La posibilidad de reconstruir el campo de la pedagogía, a partir del reconocimiento de las potencialidades y desarrollos de los movimientos político-pedagógicos latinoamericanos, es mencionada por Mejía (2009), quien ve en ellos ámbitos de interlocución y repercusión de multiplicidad de praxis pedagógicas, en donde las redes constituyen espacios de construcción de saberes, de tramas de experiencias, relaciones y sentidos en las cuales sujetos, instituciones y grupos redefinen su propia identidad al involucrarse y vincularse entre sí y con otros.

Ellos ponen a dialogar diferentes formas de saber y de nombrar el mundo junto a las experiencias escolares, generan ecologías de saberes (De Sousa Santos, 2006), estableciendo conversaciones horizontales para la "configuración plural de saberes críticos" (De Sousa Santos, 2009). Las redes constituyen espacios donde el colectivo construye discursos que lo liberan de aquello que Paulo Freire había enunciado como una "educación bancaria" (Mejía, 2009), recuperando y reconstruyendo el saber de la experiencia mientras legitima el conocimiento construido en la experiencia.

Si entendemos que el conocimiento universal no existe, las diferentes formas de conocer (De Sousa Santos, 2008) permiten la reconstrucción y visibilización de las experiencias profesionales de los docentes por parte de ellos mismos. La ponderación de estos saberes contribuiría a la reflexión de la praxis y a las construcciones de resemantizaciones pedagógicas.

\section{La documentación narrativa co-diseñada por los autores de la praxis}

Las narrativas autobiográficas docentes acercan la viabilidad epistemológica, política, teórica y metodológica de una contribución situada, a la reconstrucción de la educación y pedagogía, al tiempo que a un reposicionamiento docente. En un contexto definido,

\section{6} El aprendizaje experiencial de las trayectorias personales y la biografización focalizan la experiencia de los aprendizajes escolares y de formación, en un modo de habitar el mundo 
la experiencia y las construcciones singulares de las situaciones vividas emergen en la constante biografización ${ }^{1}$, que inscribe nuestra existencia, otorgándole forma y sentido (Delory, 2014), construyéndose un saber compartido, encarnado e inolvidable.

Como menciona Delory (2014), el aprendizaje experiencial de las trayectorias personales y la biografización focalizan la experiencia de los aprendizajes escolares y de formación, en un modo de "habitar el mundo", al decir de Jorge Larrosa (2006). Las "políticas de re-conocimiento" (Fraser, 2002), en juego en la documentación narrativa orientada a la elaboración colectiva y plural de nuevos discursos para la pedagogía, ofrecen aportes para la producción y recreación de las comprensiones e interpretaciones de la praxis por sus propios autores. A partir de estas movilizaciones cognitivas y políticas estos colectivos de docentes pueden vincularse con otros actores, desde posiciones que les permiten reconocer y discutir diferentes formas organizativas de intervención pedagógica alternativa y transformación democrática.

En la contemporaneidad se hace necesario dar cuenta de la diversidad epistemológica y de la pluralidad político-pedagógica del campo pedagógico, se torna necesario transitar un proceso de re-significación, elaborar y desplegar un nuevo lenguaje crítico para que ayude a redefinir categorías y criterios selectivos que marcan inclusiones y exclusiones. Avanzar en políticas y pedagogías de re-conocimiento que trabajen para la visualización y reconstrucción de experiencias de la praxis, difícilmente puede llevarse a cabo si ella es regulada solo por los criterios y reglas de validez y legitimidad de un campo académico.

Esto demanda abrir una conversación pluralista en torno de los posibles aportes de políticas y pedagogías de re-conocimiento, significados en permanente configuración a partir de la participación para describirlas, reconstruirlas, documentarlas y problematizarlas

1 Hablar de construcción de experiencia remite al término de investigación biográfica y proceso de biografización. Cada sujeto se apropia de su experiencia al atravesarla y capturar aquello que vive, conoce y experimenta. Los procesos por los cuales "biografiamos" las situaciones y acontecimientos de nuestras experiencias nos habilitan para darles forma y otorgarles sentido. Para Christine Delory el término biografización y el verbo biografiar remiten a la idea de que: "Cada quien vive la situación como (...) personal, razón por la que es considerada en tanto experiencia singular (...) en las representaciones que cada quien se hace de su existencia y en la historia que se construye, en lo que llamo su biografía, [su] escritura de la vida. [Es necesario comprender] cómo cada uno biografiza (...) no cesamos de biografiar lo que vivimos inscribiéndolo en el curso de nuestra existencia y, más precisamente, de darle una forma y un sentido en la historia que no paramos de escribir de nuestra vida. Denomino biografización al conjunto de operaciones y comportamientos por medio de los cuales los individuos trabajan para darse una forma propia en la que se reconocen a sí mismos y se hacen reconocer por los otros. (...) La biograficidad es, así, el código personal según el cual "leemos" y "hablamos" de las experiencias nuevas" (2014). en tanto experiencias de la praxis pedagógica que intervienen con sus discursos y prácticas en el campo de saber y de poder de la pedagogía (Suárez, Vassiliades y Vázquez, 2009), y generar, desde allí, conversaciones, temáticas y debates que aporten otros sentidos.

Boaventura de Sousa Santos (2008 y 2009) desarrolla argumentos que abonan a tal desplazamiento, implicando la construcción de una epistemología pragmática y hermenéutica que evalúe el conocimiento en función de su encuentro con otras prácticas, sujetos y saberes, y que promueva el reconocimiento plural y la valoración simbólica de experiencias y sujetos sociales.

En estenuevoterritorio epistemológicolavalidez deun conocimiento ya no será independiente de los efectos políticos y prácticos que produce. Entonces, ¿cómo pensar las alternativas? Como señala De Sousa (2008), no existen conocimientos universales, se hacen necesarias nuevas intervenciones epistemológicas, en tanto que lo que ignoramos y sabemos es siempre respecto a una determinada forma de conocimiento, en referencia a una cierta forma de ponderar el saber legitimado desde una posición epistemológica etnocéntrica, desde la cual se definen cuáles son las voces y saberes validados y cuáles serían de no saber, excluidas de la palabra bajo la lógica hegemónica que subyace como la racionalidad indolente que Lander (2003) y Quijano (2003) denominan "colonialidad del poder".

Si el lugar de los actuantes, en tanto productores e intérpretes de discursos, les puede reposicionar como sujetos de la educación que co-crean una multiplicidad de narrativas plurales, alternativas y polifónicas sobre el hacer y el pensar docente en términos pedagógicos y políticos (Novoa, 2003); la documentación narrativa, eje de la perspectiva epistemológica del giro interpretativo (Geertz 1994), podría resaltar aspectos irrepetibles de las experiencias vividas por los docentes y de las comprensiones e interpretaciones que construyen y reconstruyen como autores actuantes.

Una estrategia de formación horizontal y de desarrollo profesional de docentes desplegaría, potencialmente, una modalidad de investigación cualitativa que ligue narrativas e interpretaciones docentes. Las narrativas que articulan los tiempos de los sujetos construyen sentidos en discursos como "textos a interpretar" (Ricoeur, 2001), y, dado el carácter activo y reflexivo de ellos, se plasman en las realizaciones prácticas que dan voz a las dimensiones personales y subjetivas. 


\section{El por-venir de "las narrativas"}

Partiendo de la definición de campo de Pierre Bourdieu, comencé a releer mis relatos (auto) biográficos de experiencias pedagógicas a la luz de la Tecnología Educativa, teniendo en cuenta que, como campo, se trataban de una construcción situada en un contexto socio-histórico y cultural. En 1995 Litwin decía que tal ejercicio era: "El cuerpo de conocimientos que, basándose en disciplinas científicas referidas a las prácticas de enseñanza, incorpora todos los medios a su alcance y responde a la consecución de fines en los contextos socio-históricos que le otorgan significación”.

En cuanto a mí, me formé simultáneamente en el campo de la salud, en el de la educación y, por el sendero espiralado de la vida, transité como alumna; planes pilotos, reformulaciones pedagógicas y nuevas modalidades que existieron en el sistema educativo público de la actual Ciudad de Buenos Aires. Quizás por eso cuando me preguntan de cuál campo académico provengo la imagen se asemeja más a un cuadro de Kandinsky que a uno de Velázquez.

\section{De cómo llegué hasta aquí: ¿Alguna vez, viste un conejo blanco?}

Cuando me preguntaste cómo llegué hasta aquí, respondí: ¿̇lguna vez viste a un conejo blanco? Intenté recordar cuándo comencé a compartir ideas, propuestas o investigaciones en un escrito y fue como bucear en una historia en la cual van surgiendo escenas en mi memoria. Ellas no conocen un orden cronológico o un entonces; un objeto, un lugar, un aroma, un sonido, desatan infinitas combinaciones que van, desde aquella secuencia sonora creada casi a hurtadillas en las teclas de una Smith -mimada y prohibida reliquia de mi abuelo-, hasta esas ponencias que perdí la cuenta de cuantas veces corregí y se transformaron en una publicación o en una charla. En definitiva, dejaron de ser del todo mías para ser de todos. Otras huellas aún perduran solo para mí.

La tarde pintaba cálidos rumores cuando llegó un correo electrónico, allí preguntabas si era yo y, como si el tiempo hubiese quedado suspendido bajo el efecto estremecedor que décadas atrás tenían nuestras charlas, respondí: "Sí. La misma”. A partir de ahí, lo urgente, que era rutina, me vio zarpar a otras realidades, a otros decires, a otras miradas, a otras formas de interpretar el mundo.

Cuanto más me resistí a la idea de volver a escribir, de hablar, de bucear en mi historia, fue inquietante cómo cobró múltiples formas tu presencia y el sentir frente a un papel blanco, como conejo de algodón de la misma incertidumbre y vértigo, mientras un laberinto de profundo verde intenso me animaba a recorrerlo. Documentaciones, notas y narrativas, fragmentos escondidos en ese laberinto de recuerdos que puede ser la mente humana, se hicieron visibles nuevamente.

Entonces las palabras fueron frases, ideas que entramaron y construyeron sentidos de convergencia y divergencia. Un rediseño sostenido, perfilado con las huellas de otras voces en diálogo, de otros escenarios, de este escenario. Esta es la trama de experiencias y saberes colectivos en que vengo siendo. Tu invitación, mi regreso y, así, esa página en blanco de ese primer día cobró vuelo propio y se multiplicó en relatos y narrativas; escuchados, leídos, narrados, reconstruidos y recreados en historias cuya paleta de colores, hoy, es una composición polifónica. Este ser entre campos académicos deviene en estas narrativas, como ejercicio de esta escena y de otras sucesivas, simultáneas, ensambladas en vivo, en la ubicuidad de la red, y se devela como saltos en el horizonte de los paisajes que vivencio.

Promediando la lectura y análisis de experiencias que se adscriben a la tradición crítica, nuevamente emerge la pregunta y la interpelación tiene voz en capas de recognición. Las narrativas de experiencias pedagógicas me plantean un nuevo desafío, pues las pienso en imágenes; texturadas de aromas, móviles, de colores sonoros. Mis bosquejos, diagramas y diseños toman otra dimensión y un polifacético mundo arte visual crece a mi alrededor, en objetos culturales enriquecidos exponencialmente y mediatizados por tecnologías, entonces emergen las voces de todos los sentidos y registro las escenas digitalmente, intentando interpretarlas en el instante justo. Los lenguajes se potencian y complementan, ya no soy la misma; los sujetos sensipensantes emergimos en emociones fusionadas. La convergencia, los plurilenguajes, la transmedia, nos tiene crítica, reflexiva y creativamente enredados en narrativas.

La estética visual y la perspectiva ético-político-pedagógica de los lenguajes me devuelven a investigaciones previas, veo en retrospectiva que en los años noventa los objetos culturales nos delineaban un contexto muy diferente al actual. Las narrativas no se derramaban mundialmente en plataformas como Netflix $y$, entre las escenas de las películas que veíamos juntos, apareció el recuerdo de aquel documental que en el inicio de mi carrera docente quisiste que viéramos para despertar mi interés. Dirigido por Mario Piazza (1991), relataba las experiencias en la escuela Carrasco de Rosario en la primera mitad del siglo XX. La escuela de la señorita Olga fue la narrativa audiovisual que evidenciaba la innovación pedagógica que definió una época y continúa teniendo implicancias en la actualidad. 
Olga y Leticia Cossettini (2001) encontraron "inspiración” en las obras de Gentile y Radice: "renovaron nuestro pensamiento y nos ayudaron..., "nos han guiado" en "una nueva manera de hacer, de vivir, de enseñar en la escuela”. Más allá de lugares y tiempos, se trata de encuentros con otros en los que se puede aprender; que inspiran o modifican formas de percibir y hacer las cosas; que permiten probar y experimentar con la guía o ayuda de alguien que cuenta, nos cuenta, lo que experimentó (Alliaud, 2011).

Todos estamos hechos de historias por narrar, yo defino nuevos y potentes recorridos. Mis narrativas, como el "gira tiempo" ${ }^{2}$ de Hermione en Harry Potter, se inscriben en la lógica de bucle y crean múltiples escenas que producen rupturas de categorías universales de tiempo y espacio. Emergen en versiones heterogéneas sin perder su legitimación ante la pregunta: ¿Cómo siguen?, y, así, alcanzan esa tensión en vilo en que las series de este siglo nos tienen de hermeneutas de nuevos formatos narrativos. Entonces, si tengo que responder a tu pregunta, te diré: ¡Los desafíos me inspiran!

Desde la pedagogía de la experiencia, que permite reconocer, explorar y expresar el vínculo entre experiencia y saber, definimos que todas ellas son formativas, al conducir a construcciones y transformaciones de sí en las trayectorias educativas. La investigación narrativa es movida por una búsqueda y por el deseo de profundizar en algún aspecto de lo vivido, permitiendo que su significado se desarrolle en la ampliación de diversas dimensiones que su exploración despierta y evoca (Contreras, 2013).

El saber que comunica esta pedagogía existe en una relación de resonancia. Es un saber del narrador que lo construye entre su experiencia y el pensar, otorgándole sentido, y de quien escucha y vincula la experiencia por-vivir, sus saberes y los nuevos significados que define. La pedagogía de la experiencia opera así sobre la propia práctica como posibilidad de conectar al sujeto con el saber de la experiencia. Hablamos de una pedagogía de la singularidad, de la conversación, de la alteridad y de la escucha, que nos interroga acerca de los saberes que los habilitan para que cada sujeto construya una experiencia singular.

La escucha marca el desafío de hacer de las prácticas de enseñanza una vivencia, una experiencia. Al decir de Larrosa (2003) es necesario convertir en desconocido lo demasiado conocido y problematizar lo evidente. Renovar las palabras y escribirlas como por primera vez e interpretarlas de un modo inédito. La pausa conjuga el acontecimiento del por-venir y el abrirse a lo que viene.

\footnotetext{
2 El giratiempo es un objeto mágico que Hermione Granger recibe de la profesora McGonagall en la saga de Harry Potter; le permite viajar en el tiempo, produciendo formas alteradas en las narrativas, siguiendo la lógica de bucle.
}

En este punto, como Supervisora Escolar de escuelas públicas de nivel inicial de la Ciudad Autónoma de Buenos Aires, es que me pregunto: ¿Qué recorridos habría que atravesar para que la investigación narrativa autobiográfica sea sustantiva a las prácticas docentes, y la formación continua, entendida como sustantiva al desarrollo profesional?; ¿qué procesos ha vivenciado "la narrativa" hasta constituirse en "las narrativas", en movimientos que, con el aporte de las tecnologías, las reconfigurarían en objetos culturales contemporáneos?

Y las preguntas no paran: ¿Qué por-venir proyectan y aportan al campo pedagógico las narrativas transmedia definidas por Scolari (2013)?; ¿qué aportes ofrecerían a la visibilización de la actual cultura pedagógica situada, y a la tensión saber-reposicionamientodiscurso, las documentaciones narrativas co-diseñadas por sus propios autores?; ¿qué "posición de sujeto" (Laclau y Mouffe, 2004) pedagógico podría construirse a partir de rondas de planes de discusión (Lipman, Sharp y Oscanya, 1992) creadas por los propios autores docentes, y cuáles serían sus prácticas discursivas desplegadas?; ¿qué sentidos y significados disputaría el colectivo a la lógica hegemónica?

En tal línea de análisis se entiende que la comunidad que codocumenta, a partir de estas construcciones, deconstrucciones y co-construcciones situadas, podría producir conocimiento, entonces: ¿Qué decisiones político-pedagógicas se requieren para promover un desarrollo sostenido y ecológico que promueva la resemantización del campo educativo?

Retomo lecturas anteriores, de otras tradiciones pedagógicas, y vuelvo al pensamiento de Malaguzzi cuando en 1946, luego de la Segunda Guerra Mundial, planteó la documentación como una escucha visible. Desde la perspectiva del principio de la incertidumbre pensó en la documentación como llave de lectura y valoración de procesos escolares, como instrumento de interpretación y conocimiento del lado oculto de la cultura de la infancia; afirmó que ella es "una manera ética, estética y política de pensar la educación (que) supone establecer una distancia -un nuevo punto de vista- sobre nuestro trabajo" (Malaguzzi, 2001).

Somos fabricantes de historias, menciona Bruner (2013), estamos hechos de nuestras narrativas, una dialéctica que organiza y comunica la experiencia constituyéndonos a la par que interpretamos y construimos sentidos. Al narrar construimos tramas de sentidos, siendo la documentación una interpretación y co-construcción de significados de la experiencia. Benjamín (1999) presenta al germen de la narración como provocador de reflexión y expectativa en el oyente. En un contrapunto, la conjugación del arte de narrar con el deleite de la escucha encuentra su huella en la 
adherencia del narrador al relato. La trama polifónica del narrador se funda en el recuerdo: la tradición de transmisión, el arte de narrar y su relación a flor de piel con el oyente.

\section{Perspectiva tecnológica en la praxis pedagógica y documentación narrativa co-diseñada}

La tecnología educativa se constituye como campo en la década de los cincuenta, tomando los aportes de perspectivas psicológicas conductistas y de visiones funcionalistas del campo de la comunicación. Esta configuración estaba ligada a la búsqueda de eficiencia, a la interpretación artefactual y tecnicista que le asignaba el lugar de resolución mágica de los problemas educativos desde una supuesta neutralidad acrítica. Pero ahora los tres sesgos (conductista, sistémico y tecnicista) que tuvo en su origen se desplazan para hacer emerger el sentido político-pedagógico en un escenario de oportunidades.

Para la humanidad hoy el mundo es otro: "cambió tanto que los jóvenes deben reinventar todo" (Serres, 2013). Las revoluciones epocales, que alguna vez fueron la escritura y la imprenta, son espectadoras de la evolución de las tecnologías de la información y la comunicación. Los sujetos contemporáneos ya no hablan, escriben o leen del mismo modo, realizan complejas funciones cognitivas y ponen en juego capacidades, habilidades y estrategias que les posibilitan operar sus realidades hipertextualmente en el espacio que habitan, un escenario que ya no está regido solo por distancias métricas, sino que se remite a un espacio topológico en la ubicuidad de la red.

El campo recreado reconoce una segunda brecha que es de uso (Necuzzi, 2013) y bebe en enriquecidas posibilidades de acciones reduccionistas de brechas de exclusión (Sassen, 2015), contribuyendo a la toma de decisiones estratégicas sostenidas en el tiempo, tendientes a la democratización del conocimiento desde el ámbito de las políticas públicas.

Como expresan Serres en Pulgarcita (2013), Cobo (2016) y otros autores, en esta recreación del campo epistemológico y cultural (Maggio, 2012), el aula ya no es la misma; es necesario reflexionar sobre la manera de repensar y rediseñar las instituciones escolares. Un punto de partida clave para este gran desafío consiste en ser conscientes de que los sujetos y la escuela, como organización, están en constante movimiento y de que todo conocimiento es provisional.

Si, como se ha venido sosteniendo, el mundo es otro distinto al de apenas una década atrás, deberíamos preguntar: ¿qué fundamentos conducen a sostener que los estudiantes aprenden igual que en otras épocas, en un tiempo lineal y homogéneo, de una única forma y en los mismos escenarios? Puentes tecnológicos se abren desde el diseño de entornos digitales en donde se piensa la inclusión, ya no desde el equipamiento y posibilidad de conectividad, sino a partir de la disminución de brechas en el uso potente de las tecnologías, que se constituyen en mediadores socio-culturales y enriquecedores de las propuestas pedagógicas.

En este sentido, las TIC desafían los límites temporales y espaciales; en tanto ubicuas, también enriquecen las oportunidades de aprendizaje a lo largo de toda la vida (Burbules, 2014). En una sociedad caracterizada por formas predatorias de exclusión (Sassen, 2015), esta arquitectura rizomática (Deleuze y Guattari, 1992) pone a disposición una multiplicidad de voces autorizadas y de la inteligencia colectiva (Lévy, 2004).

Nos toca habitar un mundo en donde las nuevas posibilidades de acción son la base de un sostenido proceso de transformación cultural, el cual requiere construir nuevos lazos de ciudadanía crítica digital. La convergencia expone la coexistencia de medios digitales que entran en relación con, y vinculan a, comunidades protagonistas de una cultura participativa (Jenkins, 2016); como afirmó Morin: "La comprensión intelectual requiere aprehender conjuntamente el texto y el contexto, el ser y su medio, lo local y lo global, y la comprensión humana requiere esa comprensión, pero también y, sobre todo, comprender lo que vive el otro" (2016).

En el mismo sentido, Maggio (2012) devela los rasgos distintivos y desarrolla el concepto de "enseñanza poderosa”, refiriéndose así a un enfoque teórico actualizado, una forma de abordar propia de un campo, de una disciplina, cuyo conocimiento y modo de producción es de carácter provisional; la cual permite una mirada en perspectiva y el análisis desde diversos campos y puntos de vista. La construcción de la propuesta entonces se formula en tiempo presente y ofrece una estructura didáctica inédita, original. En estrecho compromiso con la subjetividad conmueve, transforma y perdura.

Una propuesta genuinamente formativa debería contribuir a construir puentes con lo transversal de las tecnologías, facilitando en una población masiva la edificación colaborativa de conocimiento y la documentación diseñada (Maggio, 2018). Procesos constantes de descentración y recentración que complejizan en forma sostenida las capas de meta-análisis (Litwin, 1997) y el trabajo retrospectivo interpretativo (Jackson, 1995) en reconstrucciones que deconstruyen las experiencias.

Así también, a partir de las experiencias, es necesario generar espacios, dispositivos y estrategias de profundo análisis junto a los directivos, fortaleciendo el rol asesor que los tiene como 
protagonistas. En tal sentido, Fullan (1993), destaca las experiencias compartidas, las relaciones de confianza, la responsabilidad y la transparencia como pilares para concretar una reforma exitosa.

En tiempos de alta disponibilidad de las teorías de la información y el conocimiento, el saber se establece en relaciones de horizontalidad que nos ubican en un análisis más profundo. Desde esta mirada epistemológica los procesos de transformación no son lineales; cargados de incertidumbre y emoción, a veces son perversos, multifacéticos y complejos, exponiendo intrínsecamente la incertidumbre, la ansiedad y el temor (Fullan, 1993); por eso es importante "aprender a navegar en un océano de incertidumbres a través de archipiélagos de certeza” (Morin, 2016). Ese aprendizaje, justo a tiempo, pluricontextualizado y con otros (Lion, 2012), exige pensar en red, surfeando entre contrapuntos y micronarrativas con el horizonte de un infinito abanico de posibilidades que se despliegan ante nosotros y posibilitan el co-diseño de discursos emergentes $^{3}$.
El planteamiento relacional de Castells (2009) sobre la tensión entre individuo y colectivo, cuestiona las nuevas construcciones de ciudadanía y culturas identitarias en los escenarios contemporáneos, entendiendo que ningún proceso de formación es posible en soledad. El conocimiento se construye colectivamente a partir de pensar, intercambiar y producir obras con significados compartidos por todos los sujetos involucrados. Generar perspectivas a futuro desde el presente propicia la conformación de comunidades de práctica profesional, ofreciendo espacios, entornos y tiempos adecuados, convirtiéndose en desafío.

De esta forma, las prácticas se discuten y los obstáculos son tratados como problemas que se constituyen en desafíos de la praxis. La complejidad se aborda colectivamente y, en ese hacer colectivo, se genera una trama de comprensión. Así, las tecnologías, como objetos culturales mediatizadores, amplían las posibilidades de visibilizar a la escuela pública resignificándose, generando igualdad de oportunidades en la construcción de ciudadanía, a partir de construcciones originales y comprensiones profundas.

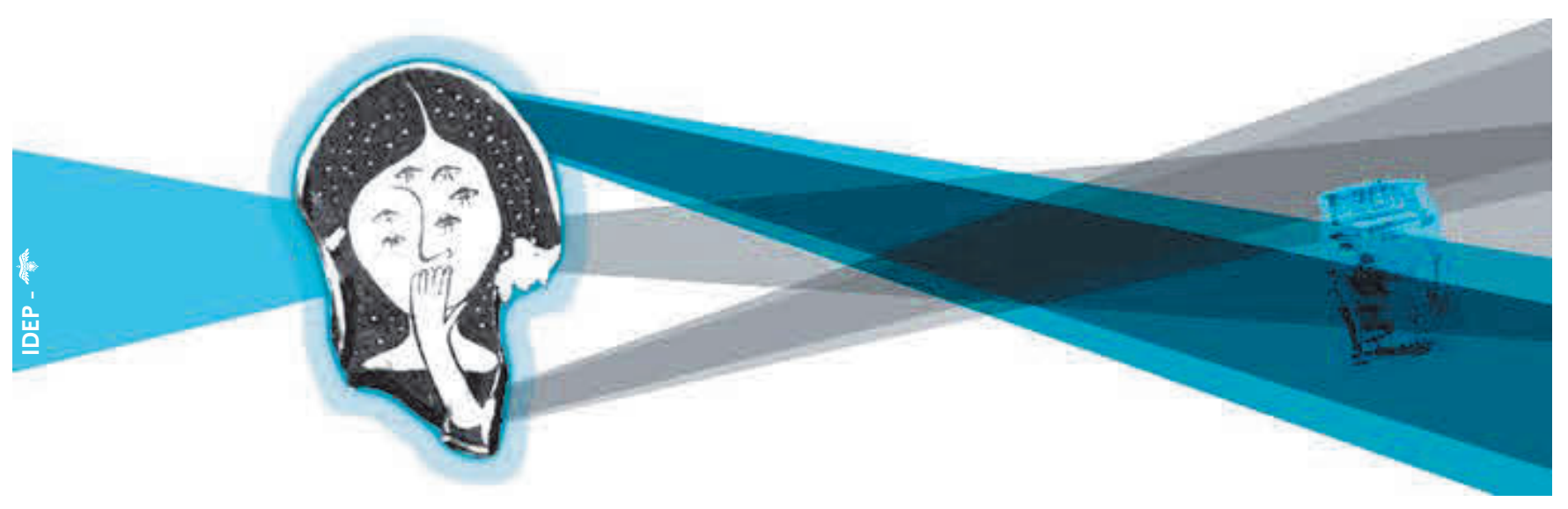

3 Me refiero a experiencias y discursos pedagógicos emergentes, tomando prestado el concepto de tendencia artística, que buscan encontrar su propia voz en un constante flujo de recreación, que en un sentido freireano emergen en el universo hegemónico. Podemos entenderlas como experiencias y discursos pedagógicos disruptivos, formatos escolares atípicos o prácticas reinventadas. 


\section{Últimas reflexiones. Perspectivas situadas}

Pensar los docentes en el siglo XXI requiere poner en juego enfoques desde la complejidad. La formación continua y el desarrollo profesional encuentran nuevos y diversos entramados epistemológicos que atraviesan las prácticas, en los cuales deben promover procesos de comprensión profunda, cognitivos, emocionales y sociales respecto de las prácticas de enseñanza y la tarea de enseñar.

Este escenario demanda recrear lazos entre escuela, educación y sociedad; vínculos que pueden fortalecerse mediante la aparición de movimientos creados colaborativamente, cuyo propósito sea la construcción colectiva de conocimiento anclada en el uso activo, exploratorio, creativo y reflexivo de las tecnologías. Construcciones, del discurso autobiográfico, deconstrucciones y recreaciones de saberes e interpretaciones situadas.

Así, es deseable que el desarrollo de la ciudadanía digital se construya y expanda en el despliegue de comunidades de práctica crítica, reflexiva y creativa. Alentado en la convivencia, las relaciones horizontales y el trabajo colaborativo, podría marcar tendencias culturales que tensionen la agenda de las políticas públicas mientras visibilizan la pluralidad de voces que reconfiguran el campo educativo.

Se habla de proyectos de trasformación social y cultural, de creación de sentidos desde una perspectiva de aprendizaje dialógico que involucre escuela y sociedad, considerando comunidades de aprendizaje (Valls, 2010) donde el descubrimiento y creación encuentren sostén en la escucha interesada, la revisión continua de los puntos de vista indagados (Lipman, et al., 1992) y la producción e interpretación de su propio hacer, configurando contextos comunicativos de atención mutua (Connelly y Clandinin, 1995), terreno de intersubjetividad dinámica, de investigación "cognitiva, lingüística, personal, social, emocional, política” (Kennedy, 1997) en la formación continua, la reflexión crítica de las prácticas y la investigación desde la escuela.

Desde la pedagogía de la experiencia, la escucha y la meta interpretación, el co-diseño de documentación pedagógica podría marcar el desafío para las prácticas de enseñanza. Una vivencia, una experiencia, una estructura dialógica donde los docentes produzcan obras originales en co-autoría, en relación de horizontalidad, en territorio, para producir discursos pedagógicos (Pace y Cali, 2018a y 2018b). En estos movimientos se piensa la gestión "supervisiva" como la construcción de una cultura que promueva procesos de desarrollo profesional, investigación docente y reposicionamiento político-pedagógico.

Aprender otras formas de construir saberes en el siglo XXI también es construir conocimientos en la sociedad red (Castells 2009), lo cual, ante los nuevos aportes tecnológicos, impacta en las comunidades científicas y conforma parte de la trama epistemológica contemporánea. Pensar en las tecnologías como objetos culturales y puentes también es visibilizar expulsiones sociales (Sassen, 2015) e inclusiones tecnológicas; es entender que la documentación narrativa co-diseñada pedagógica podría ser una potente obra de autor a deconstruir, resignificar e interpretar como obra inconclusa. Así, al entender lo dicho por Hoyuelos (2007), continuamos preguntando cómo ese mismo movimiento puede contribuir a la resemantización de la tradición crítica desde una perspectiva situada:

A través de la documentación se desvela una escuela que quiere argumentar su trabajo más allá de las palabras, una escuela que piensa, que reflexiona, que aprende en el camino: una institución educativa que sabe ponerse en discusión pública, capaz de escuchar y dialogar con democracia, construyendo procesos de recíproca confianza. 


\section{Referencias}

Alliaud, A. (2011). El saber de la experiencia narrativa, investigación y formación docente. Buenos Aires: Departamento de Ciencias de la Educación, Universidad de Buenos Aires.

Arias, A., y Alvarado, S. (2015). Investigación narrativa: apuesta metodológica para la construcción social de conocimientos científicos. Revista CES Psicología, 8(2), pp. 171-181.

Barthes, R. (1996). Introducción al análisis estructural de los relatos. Análisis estructural del relato. México: Ediciones Coyoacán, pp. 9-43.

Bauman, Z. (2015, Septiembre 4). Dilemas del vecino contemporáneo. Revista Ñ. Obtenido el de Abril de 2017 desde http://70aniversario.clarin.com/revista-enie/\#zygmunt-bauman-dilemas-del-vecinocontemporaneo

Benjamin, W. (1999). El narrador. Para una crítica de la violencia y otros ensayos. Madrid: Taurus.

Bruner, J. (1997). La construcción narrativa de la realidad. La educación, puerta de la cultura. Madrid: Visor, pp. 151-170.

Bruner, J. (2013). La fábrica de historias. Derecho, literatura, vida. México: Fondo de Cultura Económica.

Brynjolfsson, E., y McAfee, A. (2013). La segunda era de la máquina: trabajo, progreso y prosperidad en un tiempo de tecnologías brillantes. Buenos Aires: Grupo Editorial Temas.

Burbules, N. C. (2014). Los significados de "aprendizaje ubicuo". Archivos Analíticos de Políticas Educativas, Vol. 22, p. 104, https://doi.org/10.14507/epaa.v22.1880

Castells, M. (2009). Comunicación y poder. Madrid: Alianza editorial.

Cobo, C. (2016). La innovación pendiente. Reflexiones (y provocaciones) sobre educación, tecnología y conocimiento. Montevideo: Penguin Random House.

Cobo, C., y Moravec, J. W. (2011). Aprendizaje invisible. Hacia una nueva ecología de la educación, Vol. 3. Barcelona: Universitat Barcelona. Obtenido el 12 de Noviembre de 2017 desde www. aprendizajeinvisible.com/es/

Connelly, F. M., y Clandini, D. J. (1995). Relatos de experiencia e investigación narrativa. En: Larrosa, J. Déjame que te cuente. Ensayos sobre narrativa y educación. Barcelona: Laertes.

Contreras, D. (2013). Pedagogías de la experiencia y la experiencia de la pedagogía. En Contreras, J., y Pérez de Lara, N. (Comp.). Investigar la experiencia educativa (pp. 241-271). Madrid: Morata.

Contreras, J., y Pérez de Lara, N. (Comp.). (2010). Investigar la experiencia educativa. Madrid: Morata.

Cossettini, O. (2001). Obras completas. Santa Fe: Ediciones AMSAFE.

De Sousa Santos. B. (2006). Renovar la teoría crítica y reinventar la emancipación social. Buenos Aires: CLACSO

De Sousa Santos, B. (2008). Conocer desde el Sur. Para una cultura política emancipatoria. La Paz: CLACSO.

De Sousa Santos, B. (2009). Una epistemología del Sur. La reinvención del conocimiento y la emancipación social. México. Siglo XXI, CLACSO.

De Sousa, E. C. (2010). Modos de narración y discursos de la memoria: biografización, experiencias y formación. En Passeggi, M. C., y De Souza, E.C. (Org.), Memoria docente, investigación y formación. Buenos Aires: Universidad de Buenos Aires, CLACSO.

Deleuze, G., y Guattari, F. (1992). Rizoma. Valencia: Pre-Textos.

Delory, Ch. (2014). Experiencia y formación: biografización, biograficidad y heterobiografía. Revista Mexicana de Investigación Educativa, 19(62), pp. 695-710. 
Delory, Ch. (2016). La condición biográfica. Ensayos sobre el relato de sí en la modernidad avanzada. Introducción, Capítulos 1, 2 y 3. (XVII-39). Medellín: Editorial de la Universidad de Antioquia.

Expedición Pedagógica Nacional. (2005). Con los dedos en la filigrana. Una lectura crítica a los tejidos metodológicos de la Expedición Pedagógica Nacional. Bogotá: Universidad Pedagógica Nacional de Colombia.

Fraser, N. (2002). Redistribución, reconocimiento y participación: hacia un concepto integrado de justicia. En UNESCO, Informe Mundial sobre Cultura 2000-2001. Diversidad cultural, conflicto y pluralismo. Montevideo: UNESCO.

Freire, P. (2002). Pedagogía del oprimido. Buenos Aires: Siglo Veintiuno.

Fullan, M. (1993). Las fuerzas del cambio. Explorando las profundidades de la reforma educativa. Madrid: Akal.

Fullan, M., y Hargreaves, A. (2014). Capital profesional. Madrid: Morata.

Geertz, C. (1994). Géneros confusos: la reconfiguración del pensamiento social. Conocimiento local. Ensayos sobre la interpretación de las culturas. Buenos Aires: Paidós.

Hoyuelos, B. (2007). Documentación como narración y argumentación. Revista Aula de Infantil, No. 39. Barcelona: Grao, pp. 5-9.

Jackson, P. W. (1995). Sobre el lugar de la narrativa en la enseñanza. En Mc. Ewan, H. La narrativa en la enseñanza, el aprendizaje y la investigación. Buenos Aires: Amorrortu.

Jackson, P. W. (2002). Práctica de la enseñanza. Buenos Aires: Amorrortu.

Jenkins, H., Ito, M., Boyd, D. (2016). Participatory Culture in a Networked Era: A Conversation on Youth, Learning, Commerce and Politics. Oxford: Blackwell Publishing.

Kennedy, D. (1997). Reconstructing childhood. Trabajo presentado en el VIII International Conference of Philosophy for Children, University of Akureyri, Iceland.

Laclau, E. (1996). Emancipación y diferencia. Buenos Aires: Ariel.

Laclau, E., y Mouffe, Ch. (2004). Hegemonía y estrategia socialista. Hacia una radicalización de la democracia. Buenos Aires: Fondo de Cultura Económica.

Lander, E. (Comp.). (2003). La colonialidad del saber: eurocentrismo y ciencias sociales. Perspectivas latinoamericanas. Buenos Aires: CLACSO.

Larrosa, J. (2003). Algunas notas sobre la experiencia y sus lenguajes. Serie Encuentros y Seminarios. Barcelona: Universidad de Barcelona, Departamento de Teoría e Historia de la Educación.

Larrosa, J. (2003). Entre lenguas. Lenguaje y educación después de Babel. Barcelona: Editorial Laertes, pp. 21$37,75-110,165-178$.

Larrosa, J. (2006). Sobre la experiencia. Revista Educación y Pedagogía, No. 18. Medellín: Universidad de Antioquía, pp. 43-51.

Lévy, P. (2004). Inteligencia colectiva: por una antropología del ciberespacio. Washington: Organización Panamericana de la Salud.

Lion, C. (2012). Pensar en red. Metáforas y escenarios. En Scialabba, A. ¿Cómo serán? El futuro de la escuela y las nuevas tecnologías. Buenos Aires: Prometeo, pp. 29-45.

Lipman, M., Sharp, A., y Oscanya, F. (1992). La filosofía en el aula. Barcelona: De la Torre.

Litwin, E. (1995). Tecnología educativa. Políticas, historias, propuestas. Buenos Aires: Paidós.

Litwin, E. (1997). Las configuraciones didácticas. Una nueva agenda para la enseñanza superior. Buenos Aires: Paidós.

Maggio, M. (2012). Enriquecer la enseñanza. Buenos Aires: Paidós.

Maggio, M. (2018). Reinventar la clase en la universidad. Buenos Aires: Paidós. 
Malaguzzi, L. (2001). La educación infantil en Reggio Emilia. Barcelona: Octaedro.

Martínez, A., y Peña, F. (Comp.). (2009). Instancias y estancias de la pedagogía. La pedagogía en movimiento. Bogotá: Universidad de San Buenaventura.

Mejía, M. R. (2009). Los movimientos pedagógicos en tiempos de globalizaciones y contrarreforma educativa (Construyendo propuestas a la despedagogización). En Martínez, A., y Peña, F. (Comp.), Instancias y estancias de la pedagogía. La pedagogía en movimiento. Bogotá: Universidad de San Buenaventura.

Morin, E. (2016). Enseñar a vivir. Manifiesto para cambiar la educación. Barcelona: Paidós.

Necuzzi, C. (2013). Estado del arte sobre el desarrollo cognitivo involucrado en los procesos de aprendizaje y enseñanza con integración de las TIC. En UNICEF, Programa TIC y educación básica. Obtenido el 18 de Octubre de 2017 desde http://www.unicef.org/argentina/spanish/Estado_arte_desarrollo_ cognitivo.pdf

Novoa, A. (2003). Textos, imágenes y recuerdos. Escritura de "nuevas" historias de la educación. En Popkewitz, T., Franklin, B., y Pereyra, M. (Comp.), Historia cultural y educación. Ensayos críticos sobre conocimiento y escolarización. Barcelona: Pomares.

Pace, A., y Cali, M. (2018a). Laboratorio de Visiones. En Tenaglia, P. (Comp.), Narrativas Pedagógicas y TIC. Experiencias de supervisión, gestión directiva y prácticas docentes. Córdoba: Editorial Brujas.

Pace, A., y Cali, M. (2018b). Asesoramientos pedagógicos co-diseñados en territorio. Trabajo presentado en el Congreso Internacional de Educación "Educación e Inclusión desde el Sur", Río Grande, Provincia de Tierra del Fuego, Antártida e Islas del Atlántico Sur, Argentina.

Piazza, M. (1991). La escuela de la señorita Olga. [Video]. Obtenido desde https://www.youtube.com/ watch? $=$ Rv2nN-yzjps

Quijano, A. (2003). Colonialidad del poder, eurocentrismo y América Latina. En Lander, E. (Comp.), La colonialidad del saber: eurocentrismo y ciencias sociales. Perspectivas latinoamericanas. Buenos Aires: CLACSO.

Ricoeur, P. (2001). Del texto a la acción. Ensayos de hermenéutica II. México: Fondo de Cultura Económica, pp. 95-110 y 127-196.

Ricoeur, P. (2007). Tiempo y Narración I. Configuración del tiempo en el relato histórico. Madrid: Siglo XXI, pp. 113-161.

Sassen, S. (2015). Expulsiones. Brutalidad y complejidad en la economía global. Buenos Aires: Katz Editores.

Scolari, C. A. (2013). Narrativas transmedia. Cuando todos los medios cuentan. Barcelona: Deusto.

Serres, M. (2013). Pulgarcita. Buenos Aires: Fondo de Cultura Económica.

Suárez, D. (2007). Docentes, narrativa e investigación educativa. La documentación narrativa de las prácticas docentes y la indagación pedagógica del mundo y las experiencias escolares. En Sverdlick, I. (Comp.), La investigación educativa. Una herramienta de conocimiento y acción (pp. 71-110). Buenos Aires: Novedades Educativas.

Suárez, D., y Ochoa, L. (2006). La documentación narrativa de experiencias pedagógicas. Una manera de indagar el mundo y la experiencia escolares. Entre Maestros, Vol. 5, No. 16.

Suárez, D., Vassiliades, A., y Vázquez, M. (2009). Conversaciones, experiencias de la praxis y horizontes de posibilidad en la reconstrucción de las pedagogías críticas en América Latina. Trabajo presentado en el VII Encuentro de Cátedras de Pedagogía de Universidades Nacionales, "La pedagogía en el pensamiento contemporáneo. Debates, encuentros y desafíos". Rosario: Facultad de Humanidades y Artes, Universidad Nacional de Rosario.

Valls, M. (2010). Comunidades de aprendizaje. Una práctica educativa de aprendizaje dialógico para la sociedad. Barcelona: Universidad de Barcelona. 